\title{
Alexander von Humboldt's charts of the Earth's magnetic field: an assessment based on modern models
}

\author{
M. Mandea ${ }^{1, *}$, M. Korte ${ }^{2}$, A. Soloviev ${ }^{3}$, and A. Gvishiani ${ }^{3}$ \\ ${ }^{1}$ Institut de Physique du Globe de Paris (IPGP, Université Paris-Diderot \& CNRS, UMR7154), \\ Case 7011, 5 rue Thomas Mann, 75205 Paris Cedex 13, France \\ ${ }^{2}$ Helmholtz-Zentrum Potsdam, Deutsches GeoForschungsZentrum - GFZ, Sektion 2.3, Erdmagnetfeld, \\ Telegrafenberg, 14473 Potsdam, Germany \\ ${ }^{3}$ Institution of the Russian Academy of Sciences Geophysical Center (GC RAS), 3, \\ Molodezhnaya St. 119296, Moscow, Russia \\ *previously at: Helmholtz-Zentrum Potsdam, Deutsches GeoForschungsZentrum - GFZ, \\ Sektion 2.3, Erdmagnetfeld, Telegrafenberg, 14473 Potsdam, Germany
}

Received: 11 May 2010 - Revised: 30 July 2010 - Accepted: 28 October 2010 - Published: 18 November 2010

\begin{abstract}
The 19th century witnessed a resurgence of interest in Earth's magnetic field. Both observational and theoretical aspects were involved, and one of the emblematic figures of this period was Alexander von Humboldt. Throughout a long life he maintained a strong interest in a broad area of subjects, however, here we are interested in his role in geomagnetism, and particularly in his pioneering contributions to charting the geomagnetic field. Alexander von Humboldt efforts in measuring and charting the Earth's magnetic field are recounted and the maps of declination, inclination and total intensity he had prepared are compared, favorably, with maps for the same epoch based on a modern model of the geomagnetic field, gufml. This modern assessment of the accuracy of von Humboldt's geomagnetic charts illustrates the importance of his work, being also our homage to the 150th anniversary of the death of Alexander von Humboldt.
\end{abstract}

\section{Introduction}

The year 2009 marked the 150th anniversary of the death of Alexander von Humboldt, the German natural philosopher and explorer. Von Humboldt was a polymath who made original contributions to geography, geology, oceanography, meteorology, and geomagnetism (Rupke, 2008; Busse, 2007). Here, we have chosen to detail von Humboldt's work with respect to charting the Earth's magnetic field and to assess the validity of his early maps. His remarkable contributions on some related topics, e.g., magnetic storms or magnetic observatories, are covered elsewhere by others.

Von Humboldt's interest in the Earth's magnetism might have started in 1796 being "Oberbergmeister" (master miner) for the region Ansbach-Bayreuth (Germany) in the years 1793 through 1797 (Malin and Barraclough, 1991). At that time he visited the Fichtel Mountains and attempted to determine, using a compass, the alignment of a block of ser-

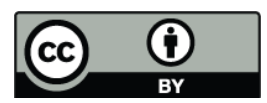

Correspondence to: M. Mandea (mioara@ipgp.fr) pentine. The unexpected behavior of the compass, which was caused apparently by the fact that the serpentine block was magnetized in a direction reversed to that of the Earth's magnetic field, was - maybe - the fact which transformed geomagnetism in a true passion for von Humboldt.

Starting in 1798, von Humboldt made magnetic measurements not only in Europe but also e.g. during his long journey through Latin America and Russia. During these voyages he carried out measurements of declination, inclination and relative field intensity. For the last two elements he used an instrument designed by Borda (Alexandrescu et al., 1996). His tenacity in measuring the magnetic field continued during his journey with Gay-Lussac in France, Germany and Italy in 1805. Another expedition, took him across the European part of Russia. During these journeys a particular attention has been paid to magnetic measurements. First geomagnetic publications by von Humboldt are a memoir written with Biot in 1804 "Über die Variation des Magnetismus der Erde in den verschiedensten Breiten" - "On the variation of Earth's magnetism at different latitudes" and "Beobachtungen über den Einfluß des Nordlichtes auf die Magnetnadel, angestellt in Berlin am 20. Dez. 1806" - "Observations about 
the influence of the polar light on the magnetic needle, carried out in Berlin on 20 December 1806". Already in the years 1806 and 1807, von Humboldt made measurements of the magnetic field in Berlin in a wooden cabin provided by the brandy distiller George in his garden. With the help of the astronomer Oltmanns, von Humboldt obtained about 6000 measurements in this period (Botting, 1973). At that time von Humboldt also studied the magnetic storm phenomenon (Lakhina et al., 2007).

In order to make this contribution self-contained, we start with some definitions and information about measuring the geomagnetic field. Aspects linked to field charting and modeling are considered, in order to underline the huge contribution made by von Humboldt in understanding the magnetic field measured at the Earth's surface. We present the maps produced by von Humboldt, and compare them with what we are able to obtain today, using more complicated techniques, and powerful computers.

\section{Geomagnetic field}

\subsection{Definition and observation of geomagnetic field components}

At any particular place and time the Earth's magnetic field can be represented as a vector $\boldsymbol{B}$ in three-dimensional space. Geomagnetic field components $X, Y$, and $Z$ are the vector projections on the northward, eastward and downward axes respectively and the total geomagnetic intensity $F$ is the vector length. Besides, the geomagnetic field at a point can be described using other elements: horizontal component $H$, magnetic declination $D$ and magnetic inclination $I$. Horizontal component, which is sometimes called the magnetic meridian, is the vector projection on the theoretical horizontal (tangent) surface. Magnetic declination is the angle in a horizontal plane between geographic north $(X)$ and magnetic north $(H)$. A compass needle aligns itself with $H$ and navigators therefore apply a variable correction to their compass courses to regain true courses; the needle was said to be north-westing (negative deviation) or north-easting (positive deviation) a certain number of degrees from true north. Finally, magnetic inclination is the angle in a vertical (perpendicular to a tangent) plane between $H$ and $F$, it is sometimes called dip (see Fig. 1). It was measured with an inclinometer (dip meter), which consisted of a magnetized needle able to rotate in the vertical plane (Courtillot and Le Mouël, 2007). Declination and inclination were the first measurements to be made (since 16 th century), which allow to obtain only directional data at a point. Intensity was first measured in a relative sense (since 1790s) by comparing the "swing time" of a needle at the desired location with that obtained at a reference site; only in 1830s Gauss developed a method for determining absolute intensity. Nowadays, directional data have been almost completely replaced by three-component

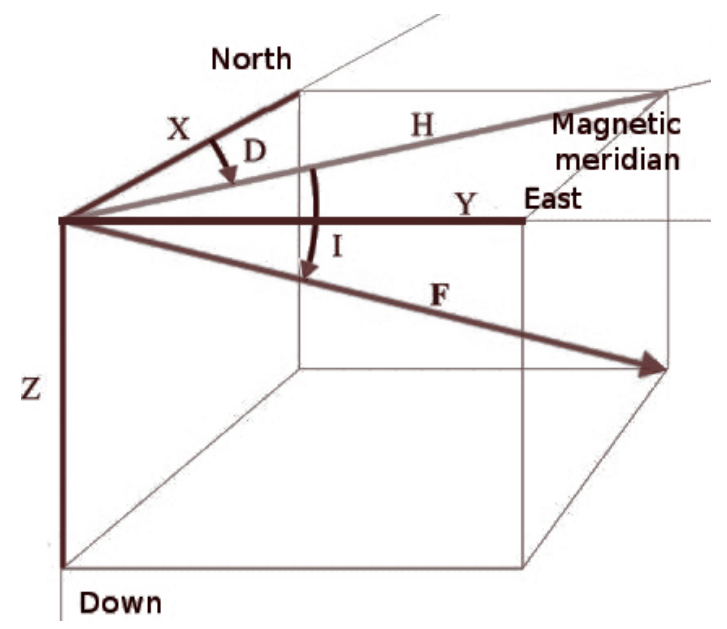

Figure 1. Representation of the three-dimensional geomagnetic vector $\boldsymbol{B}$.

data, recorded at magnetic observatories, on surveys, and by satellites (Jonkers et al., 2003; Mandea and Purucker, 2005).

\subsection{Geomagnetic data available in the beginning of the 19th century}

The most comprehensive database comprising historical geomagnetic observations currently is the one compiled by Jonkers et al. (2003). Recently, more data have been made available from some other old sources (Mandea and Korte, 2007; Korte et al., 2009). The Jonkers et al. (2003) database spans the time period from 1510 to 1930 and contains 151560 declination, 19525 inclination, and 16219 intensity measurements. Among them, some of the data are authored by von Humboldt, namely 50 inclination and 15 intensity measurements in 1799-1829. As for the data related to the 1790-1831 time-span the observations available in the database include: 27852 declinations, 1647 inclinations and 1655 relative intensities. This 42 -year period refers to the time of measurements made mainly by von Humboldt and discussed in the present paper. As for the period from 1836 to 1866 , during which the Berlin observatory operated, in the Jonkers et al. (2003) database these values are available: 28959 for declination, 4766 for inclination and 2639 for intensity.

\subsection{Charts and models}

Historically, in navigating long distances, the compass was an important instrument for indicating direction. From these measurements the first declination maps were produced. Edmund Halley, on a small sailing ship, Paramore, carried out a magnetic survey of the Atlantic Ocean and its bordering lands (Clark, 2000). From Halley's survey measurements the first magnetic map of the Atlantic was compiled. This earliest surveying magnetic contour chart was published by 
Halley in 1700, being the first published chart to include isolines of declinations (called for a while "Halleyan lines", until Hanssen used the term "isogon" for a contour line of equal declination). This map became widely used as it allowed navigators to estimate declination variation when they could not get sight of an astronomical body. A number of early declination charts were also given in Hansteen's Atlas and in Hellmann (1895) reprints.

William Whiston produced the first known charts showing the direction of magnetic inclination for south-eastern England, in 1719 and 1720. The contours are straight lines and are thus a very smooth representation of the distribution of inclination (Howarth, 2003). In 1768 Wilcke published the first approximately global inclination map, based on observations made during sea voyages.

The first chart of magnetic field intensity, covering the Northern part of the South America, was produced by Alexander von Humboldt (Humboldt and Biot, 1804). On this map the geographic and magnetic equators are indicated, and five "isodynamic zones" are defined by the average number of oscillations per minute of the magnetized needle used during von Humboldt's expeditions (Malin and Barraclough, 1991). To quote Hellmann (1909), the first "true" magnetic field intensity map was produced by Hansteen (1824) for a region of the Northern part of Europe. The intensity values shown on this chart are in relative units ("Humboldt units"), as it was produced before Gauss' demonstration on how to measure the magnetic field in absolute units (Mandea, 2007).

Present-day maps are produced from different geomagnetic field models for the main field and its secular variation. Maps produced from different models are used widely in civilian navigation systems. The whole mathematical scheme of field encoding can be briefly represented in the following way:

1. Observations of different geomagnetic field components $(D, I, F, X, Y, Z, H)$

2. Modeling geomagnetic potential (e.g., Press et al., 1992)

3. Calculation of vector field components in a particular point and at a given time.

It is still possible to model the geomagnetic potential even if only directional observations are available. Indeed, knowledge of directions of a potential field on a given smooth surface, which separates the space into a volume containing the sources and a volume free of sources, can give enough information for the whole field to be recovered within the free volume. In case of the geomagnetic field with only two poles (south and north magnetic poles) it can be recovered uniquely from directional data gathered at the Earth's surface except for a constant multiplier (Hulot et al., 1997).

The geomagnetic vector field $\boldsymbol{B}$ can be derived from a magnetic scalar potential $V$ such as $\boldsymbol{B}=-\operatorname{grad} V$. In turn, $V=$
$V^{\text {int }}+V^{\text {ext }}$ consists of a part $V^{\text {int }}$ describing internal sources, and a part $V^{\text {ext }}$ describing external sources (including their Earth-induced counterparts). Both are expanded in terms of spherical harmonics. For the internal part this yields

$V^{\mathrm{int}}=a \sum_{n=1}^{N_{\mathrm{int}}} \sum_{m=0}^{l}\left(g_{n}^{m} \cos m \phi+h_{n}^{m} \sin m \phi\right)\left(\frac{a}{r}\right)^{n+1} P_{n}^{m}(\cos \theta)$

where $a=6371.2 \mathrm{~km}$ is the reference surface radius, $(r, \theta, \varphi)$ are radial distance from the Earth's center and geographic coordinates, $P_{n}^{m}$ are the associated Schmidt semi-normalized Legendre functions, $\left\{g_{n}^{m}, h_{n}^{m}\right\}$ are the Gauss coefficients describing internal sources, and $N_{\text {int }}$ is the maximum degree and order of the internal expansion. The gufml model (Jackson et al., 2000) is such a model based on historical data and covering the time span from 1590 to 1990 with an expansion up to $N_{\text {int }}=14$.

\subsection{Geomagnetic field variations}

Geomagnetic model calculation involves huge data volume processing with inevitable agreements on parameters controlling data interpolation and filtering. Since the beginning of the era of space observations, the number and quality of data has improved significantly. Still, modeling the field of previous epochs is under constant adjustment as methods of historical magnetic field recovery are invented and improved. Visible variations of magnetic field character over time cannot be interpreted without taking the effects of all parameter agreements on precision used during modeling into account (Gillet et al., 2010). However, qualitative analysis of geomagnetic field changes can be convincingly interpreted using modeled data. The best way to appreciate these changes is to study contour maps of different field components and compare how they have evolved.

The observed geomagnetic field $\boldsymbol{B}(r, \theta, \varphi, t)$ varies at all scales of time and space. Magnetic field mapping needs global data covering periods from months to tens of years and the temporal variation associated with this scale is called secular variation. Description of secular variation field for each particular point $r, \theta, \varphi$ is extremely complicated and does not reveal any simple regularity. In this sense it is much more convenient to describe the field in terms of its spectrum, i.e. coefficients of series of field expansion by some basis (Eq. 1). Fields of function gradients are usually used as basis fields and called spherical harmonics. They are indexed by a pair $\{n, m\}$, where $n$ is degree and $m$ is order, related to the spatial wavelength in latitude and longitude. Three coefficients of the lowest degree 1 are called dipole coefficients. They change more slowly in time than the other coefficients.

\subsubsection{Drift}

Several typical patterns are recognized in a change of nondipole coefficients and one of them is called westward drift 


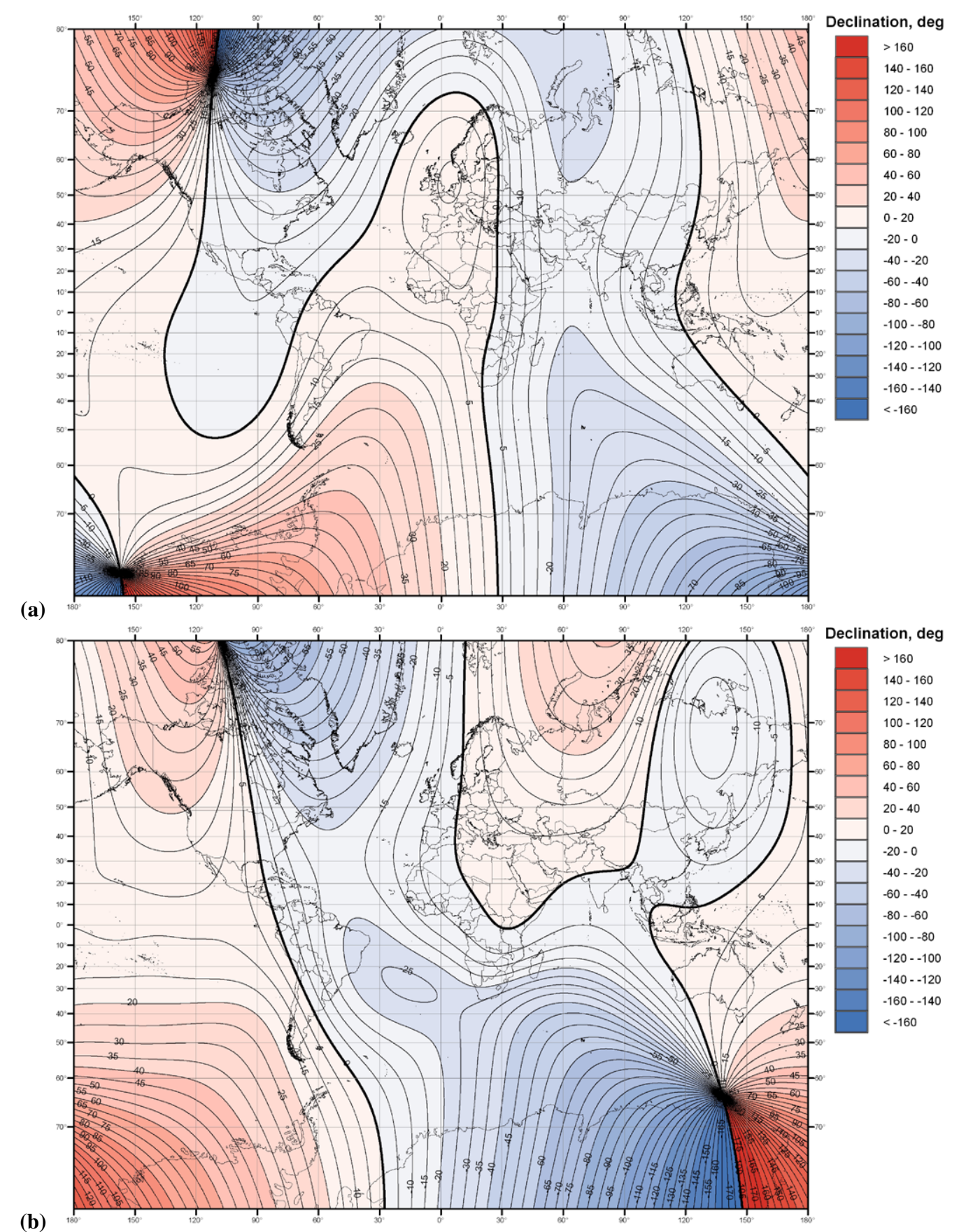

Figure 2. Observed westward drift of isogons comparing maps for 1600 (a) and 2000 (b). Agonic lines are given in bold.

(Dumberry and Finlay, 2007; Hulot et al., 2010). This phenomenon has been recognized since the time of Halley. Temporal variation of a map of non-dipole component contribution resembles (but is not limited to) a rotation in the direction east-west around the dipole axis over historical times. The rotation speed is estimated at $0.18^{\circ}$ per year. One should note that rotation around dipole axis is revealed in different dimensions of spectral expansion in different ways and the value of $0.18^{\circ}$ indicated above is just an average. Difference in drift behavior can be an evidence of non-laminarity of flow in the liquid core: indeed, vortices of different scales producing magnetic field move differently (Jackson and Finlay, 2007). The westward motion of the field is most easily seen by following the motion of the agonic lines on declination maps. It can be seen that during the 17 th century one agonic line goes over the African continent, through the Cape of 


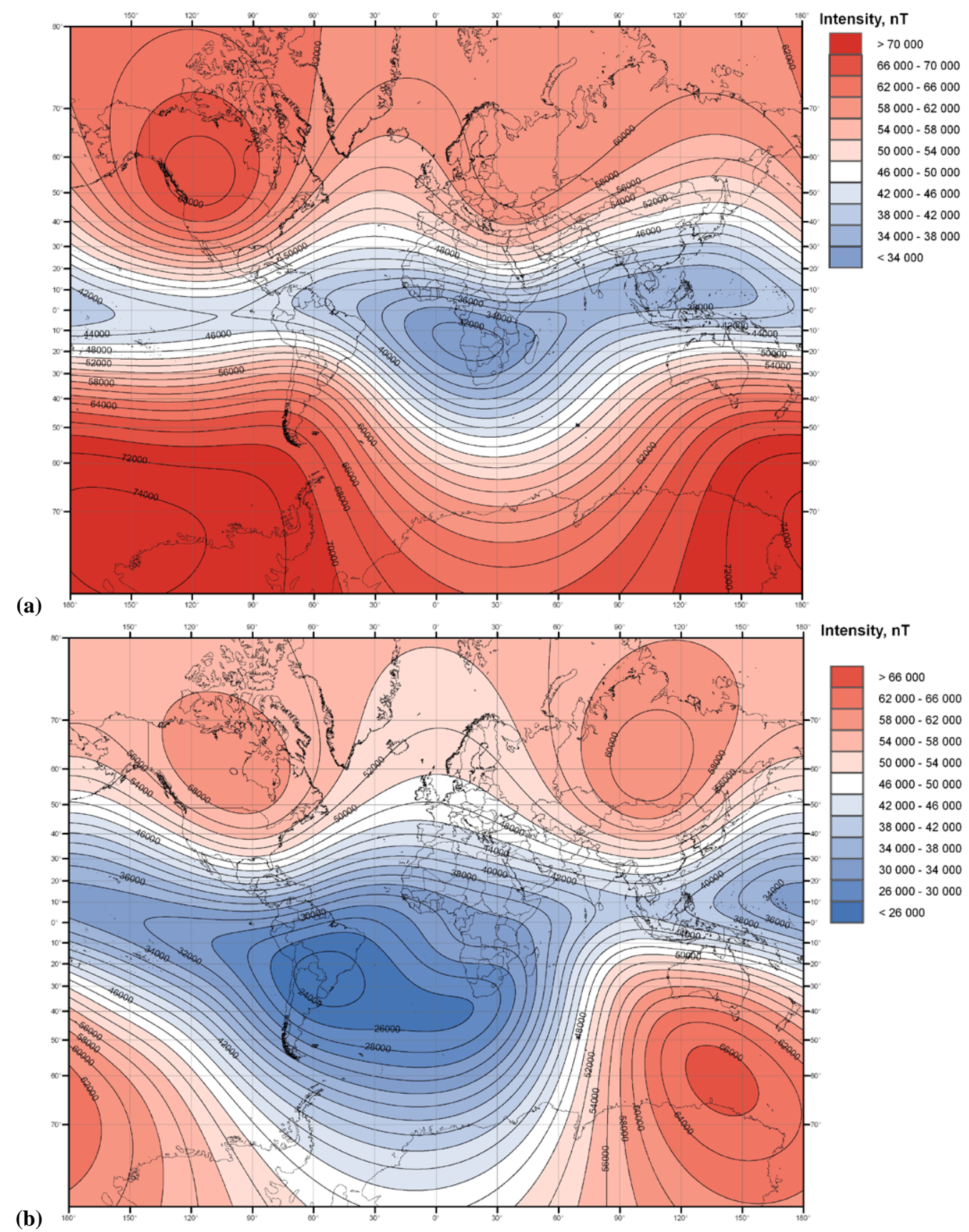

Figure 3. Observed magnetic field fading comparing maps of total intensity isodynams for 1600 (a) and 2000 (b).

Good Hope; some 400 years later, the same agonic line has moved westward, running over South America (see Fig. 2).

The maxima and minima of total intensity anomalies centered on low latitudes can also be tracked westward over the last centuries, for example, the anomaly that was present over Africa during the 17th century lies on the western edge of South America for recent times (see Fig. 3). Contour maps of the vertical component of the magnetic field are dominated by the dipole component of the field, which is unchanged by westward drift due to its axis-symmetric nature; however, the westward motion of non-dipole component of the field can still be discerned in the presented maps especially by following long-lived distortions in the magnetic equator. A southwest-to-north-east trending element of the magnetic equator can be followed from its initial location at the Indian ocean in 1650, through Africa in 1750 and the Atlantic in 1850, to the eastern edge of southern America in 1950 (see Fig. 4). 
(a)

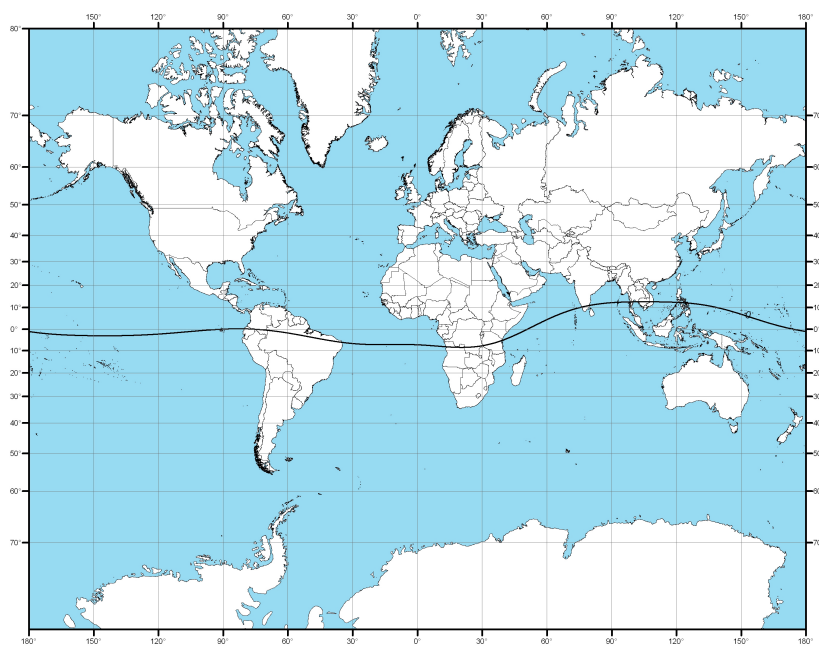

(c)

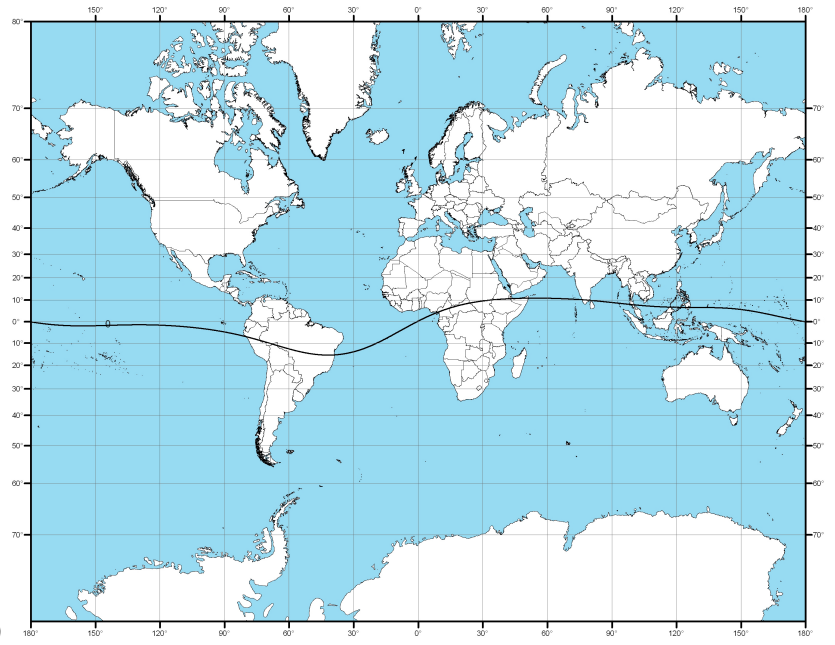

(b)

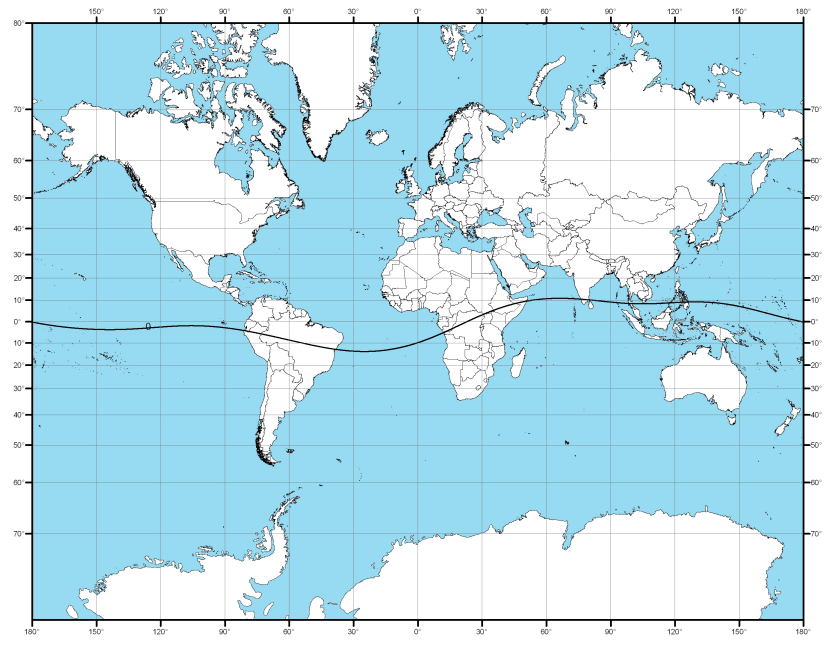

(d)

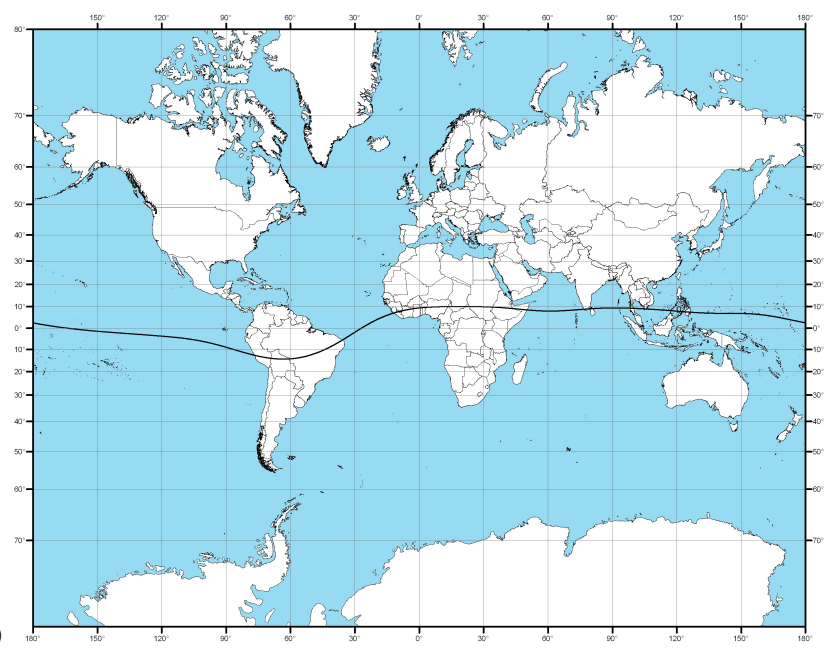

Figure 4. Observed westward drift of a south-west to north-east trending element of the magnetic equator comparing maps for 1650 (a), $1750(\mathbf{b}), 1850$ (c) and 1950 (d).

The westward drift of geomagnetic field is observed as high-amplitude features moving across the Atlantic hemisphere. In contrast, and very interestingly, the field evolution in the Pacific hemisphere is characterized by loweramplitude features and a lack of systematic secular variation (Hulot et al., 2010). Interesting to underline is that the largest contribution to present-day secular variation comes from the decay of the dipole component of the field. It has decayed rapidly at an average rate of 5\% per century since the first direct measurements of intensity at Gauss' time.

\subsubsection{Magnetic pole movements}

Magnetic poles are defined by points where the Earth's magnetic field is perpendicular to the geoid surface and they are not standing still (Fig. 2). Although precise definition of pole location is possible only with a certain abstraction from spatial-temporal scales (e.g., it should be defined what is considered to be geoid surface and in which time scale the field is averaged), a general shift of poles is quite evident: for instance during the last 100 years the north pole has obviously shifted by almost $1100 \mathrm{~km}$ (Korte and Mandea, 2008). This shift occurs rather unevenly in time, e.g. in 2005-2007 a significant increase (up to $350 \%$ ) of speed relative to the average one according to long-term observations was noted. Direction of the pole shift is not invariable; based on paleomagnetic data studies it can be stated that the magnetic poles most of the time move chaotically around the geographical poles, occasionally deviating from it significantly. Large deviations, the so-called excursions, represent short time periods in the full geomagnetic field history. However, complete polarity change took place many times: with varying degrees of reliability one can speak of at least 400 polarity changes during the last 350 million years, the very last reversal being some 780000 years ago. The duration of periods of magnetic field being in a certain polarity varies greatly as well, although had an average of around 250000 years during the last 5-10 Ma. 


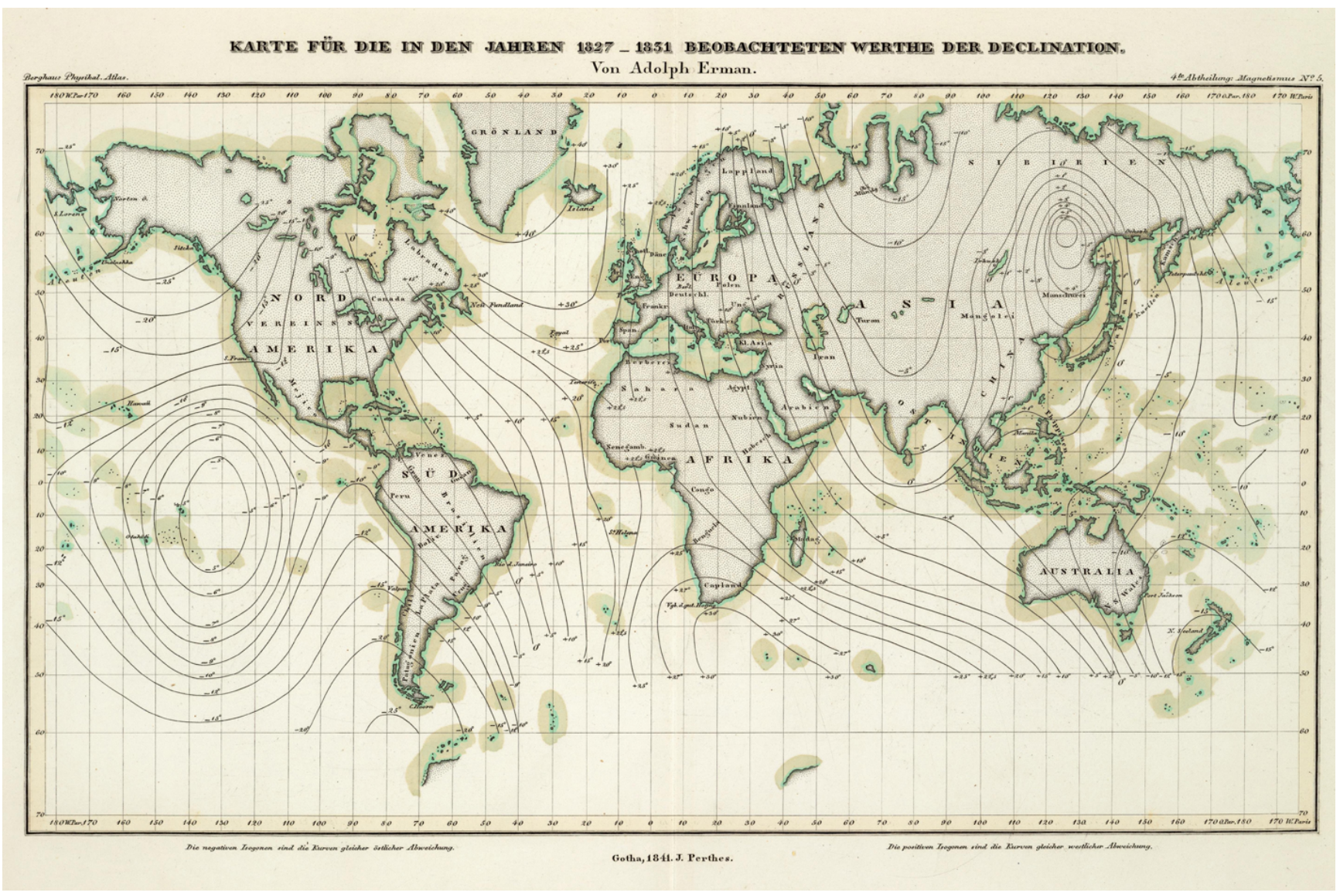

Figure 5. World map of magnetic declination measured from 1827 to 1831 published in Gotha in 1841 (Berghaus, 1837-1848) (David Rumsey Map Collection, www.davidrumsey.com, USA; Images copyright (C) 2000 by Cartography Associates).

\subsubsection{Magnetic field fading}

Comparing maps of geomagnetic field intensity for a long time interval a certain intensity decrease can be noted (Fig. 3). This started a discussion about a forthcoming next inversion (polarity change), although field models in the scale of millennia show several periods of intensity decrease. Definite arguments that the present intensity decrease leads directly to dipole inversion and will not change to increase in the near future do not exist so far (Constable and Korte, 2006; De Santis et al., 2004).

\section{3 von Humboldt and magnetic field variations}

\subsection{Maps published by von Humboldt}

During his expeditions in the Americas and Europe, von Humboldt recorded and reported on magnetic measurements: declination, inclination and field intensity. When, during the first decades of 19th century, more efforts to measured the three magnetic field components have gathered a large number of observations, they have been all mapped on a global scale, and for nearly the same epoch (different from one com- ponent to another, but all previous to 1839). Alexander von Humboldt asked Berghaus to compile the illustrations for all observations of nature and natural phenomena in an Atlas accompanying the Kosmos (Berghaus, 1837-1848). It became possible to obtain magnetic global charts by interpolating the available measurements, and in such a manner to characterize the magnetic vector in any point at the Earth's surface. This was set out by Gauss (1839), by representing the magnetic field as deriving from a gradient of a potential function. Here, Figs. 5-7 show maps reproduced from Berghaus (1837-1848), describing both directions and the relative intensity of the field, i.e. all that was known about the full magnetic field vector at that time.

The previous section described how complicated the magnetic core field and its variations are to be described. In contrast to Gauss, von Humboldt was not an analyst in the mathematical sense. However he had the ability to organize large amount of data, to chart the spatial geomagnetic field variations, and to provide useful conclusions about the field changes. For example, his observations and the total intensity map (Fig. 7) allowed him to discover the increase of the total field intensity with latitude. Only because of a large amount of data this statement was generally accepted. 


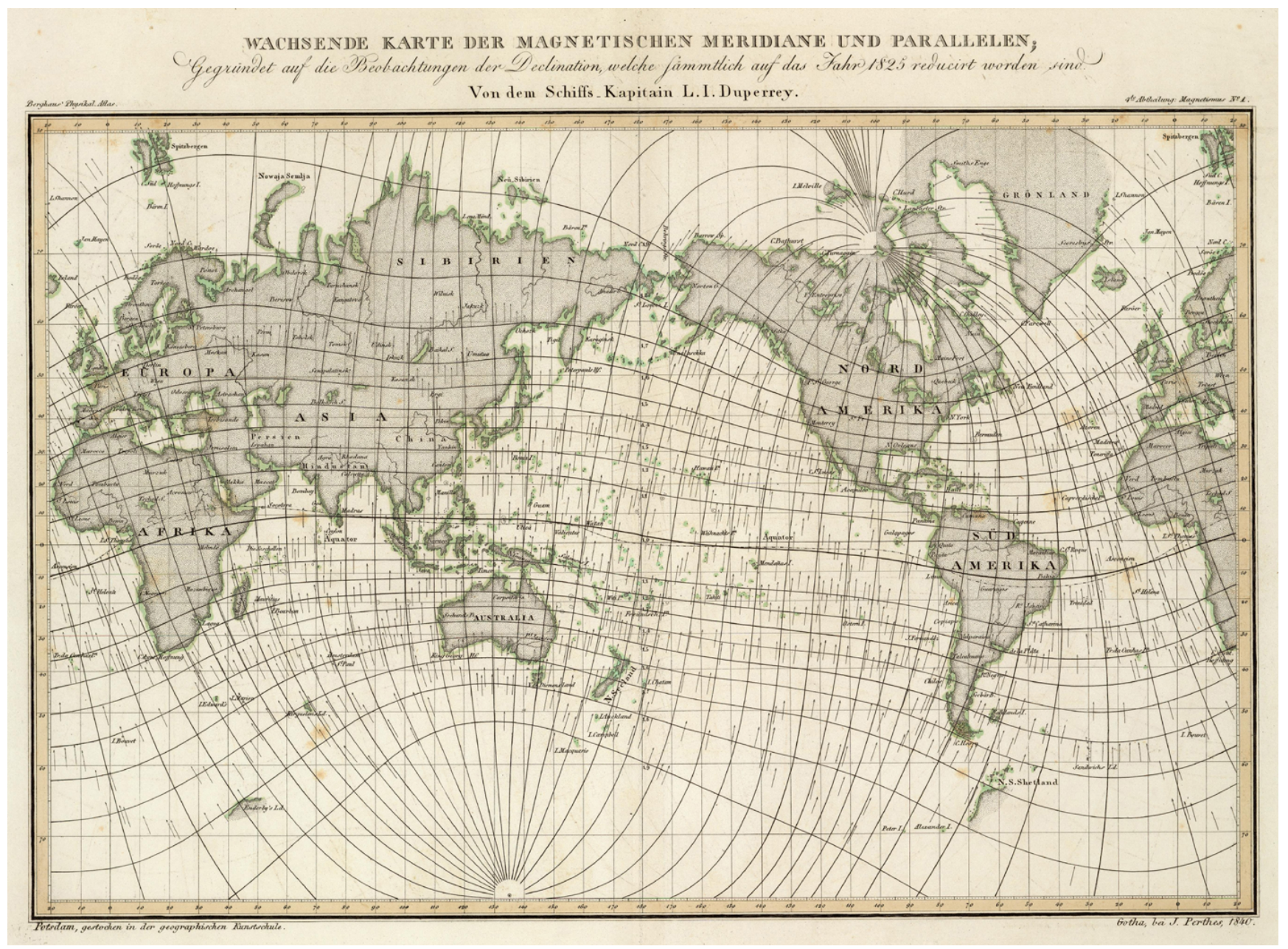

Figure 6. World map of magnetic meridians and parallels measured in 1825 published in Gotha in 1840 (Berghaus, 1837-1848) (David Rumsey Map Collection, www.davidrumsey.com, USA; Images copyright (C) 2000 by Cartography Associates).

\subsection{Maps obtained from recently published models}

The key question addressed here is the quality of the maps published by von Humboldt. It is not clear whether the temporal change of the magnetic field was taken into account at that time or not, as on the three maps the epochs are given as 1827-1831 for declination (Fig. 5), 1790-1830 for intensity (Fig. 7), but for inclination (Fig. 6) the heading says that all values have been reduced to 1825 . We compare the historical maps to predictions from the core field model gufml, which goes as far back in time as direct magnetic field measurements allow, covering the time interval from 1590 to 1990, and which relies on a quite representative data volume (Jackson et al., 2000). In order not to include artificial structure caused by data errors and insufficient data coverage, a regularization has been applied in the modeling. The result is a smoother model which shows the minimum amount of structure necessary to explain the used data. As a consequence, the spatial resolution of this model clearly changes and improves with time due to increasing amounts of (better) data. Let us note that in the modern gufm 1 model the amount of data covering the early 19th century has been largely increased (Jackson et al., 2003), comparing with data gathered by von Humboldt.

We checked the amount of change in mappings of the modeled field characteristics and found it to be insignificant from 1827 to 1831 (for declination), from 1790 to 1830 (for intensity) and from 1825 to 1830 (for inclination) at least in terms of comparison with historical maps. Thus, we give the modeled maps for intensity, declination and inclination for the year 1830. The maps are plotted in Figs. 8-10, keeping Mercator projection used by von Humboldt himself. Let us discuss these maps (computed in 2010) compared with the ones published some two centuries ago. 


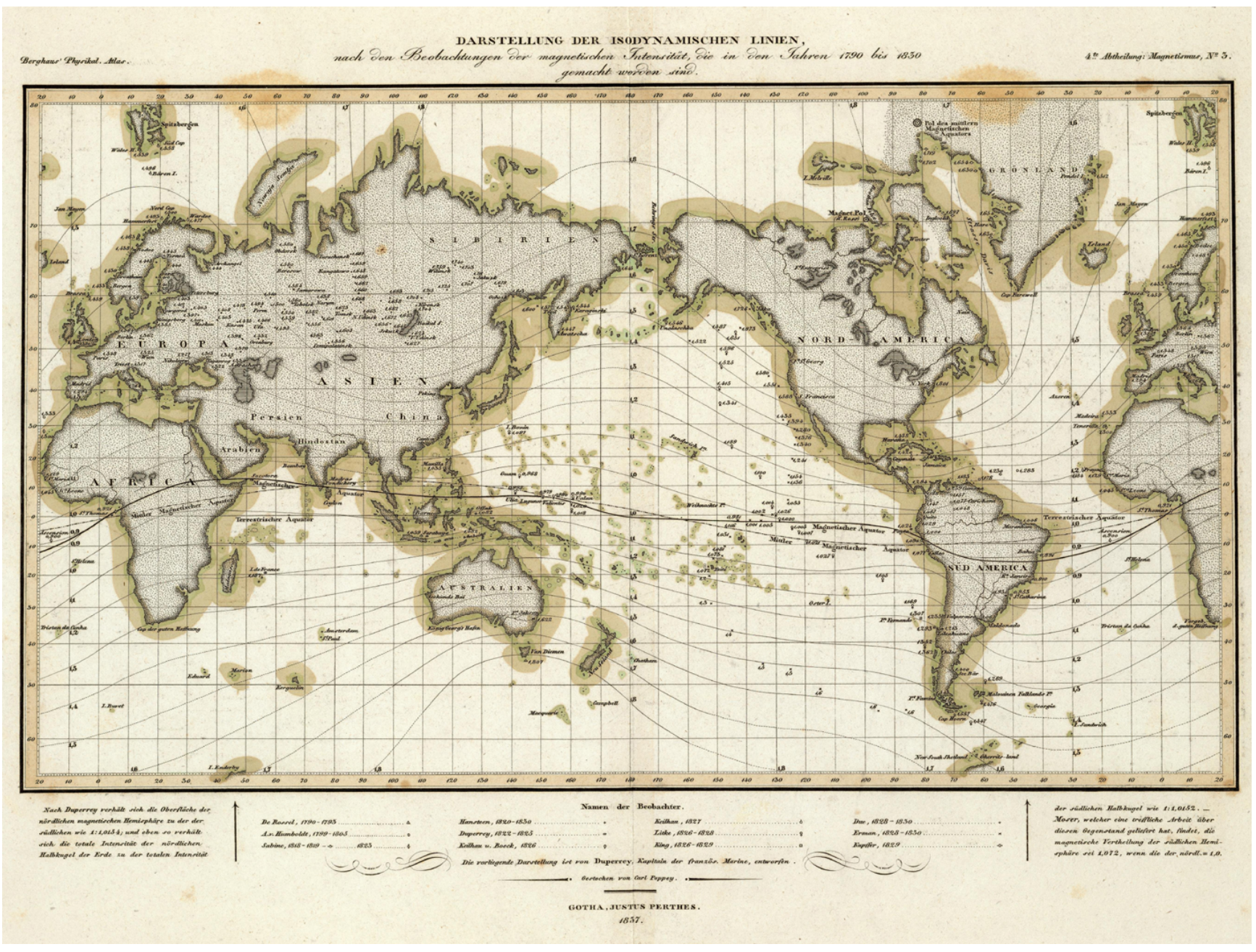

Figure 7. World map of isodynams of intensity measured in 1790-1830 published in Gotha in 1837 . The values are given in relative "Humboldt units", magnetic equator is marked with a bold line (Berghaus, 1837-1848) (David Rumsey Map Collection, www.davidrumsey. com, USA; Images copyright (C) 2000 by Cartography Associates).

\subsubsection{Declination maps}

The first observation is linked to the agonic lines (agonic line names the curve of zero declination). In Alexander von Humboldt's declination map (Fig. 5) and the one we computed from the gufml model (Fig. 8) there are three distinct agonic lines, one circling a region over the Japan Sea, another crossing European Russia, India, Australia, and the third one running from the North magnetic pole to south, over the Eastern part of North America and South America. Let us mention that in the bottom of von Humboldt's map a legend in German says that "The negative isogonal curves correspond to eastern deviation" ("Die negativen Isogonen sind die Kurven gleicher ostlicher Abweichung") and "The positive isogonal curves correspond to western deviation" ("Die positiven Isogonen sind die Kurven gleicher westlicher Abweichung"). Indeed, the isoline values on von Humboldt's map are given with the opposite sign comparing to the way it is done nowadays (Fig. 8). For instance, in both maps the values of declination over Atlantic and the African continent reach comparable values modulo, around $20^{\circ}$, but with an opposite sign. It seems this was a choice to express the magnetic variations by von Humboldt or Berhaus, the western declination by positive values and the eastern declination by negative values. It is clearly seen from von Humboldt's map that few regions are characterized by the measurements of a higher precision, e.g. " $22^{\circ}, 5$ " in northwest region of Africa. 


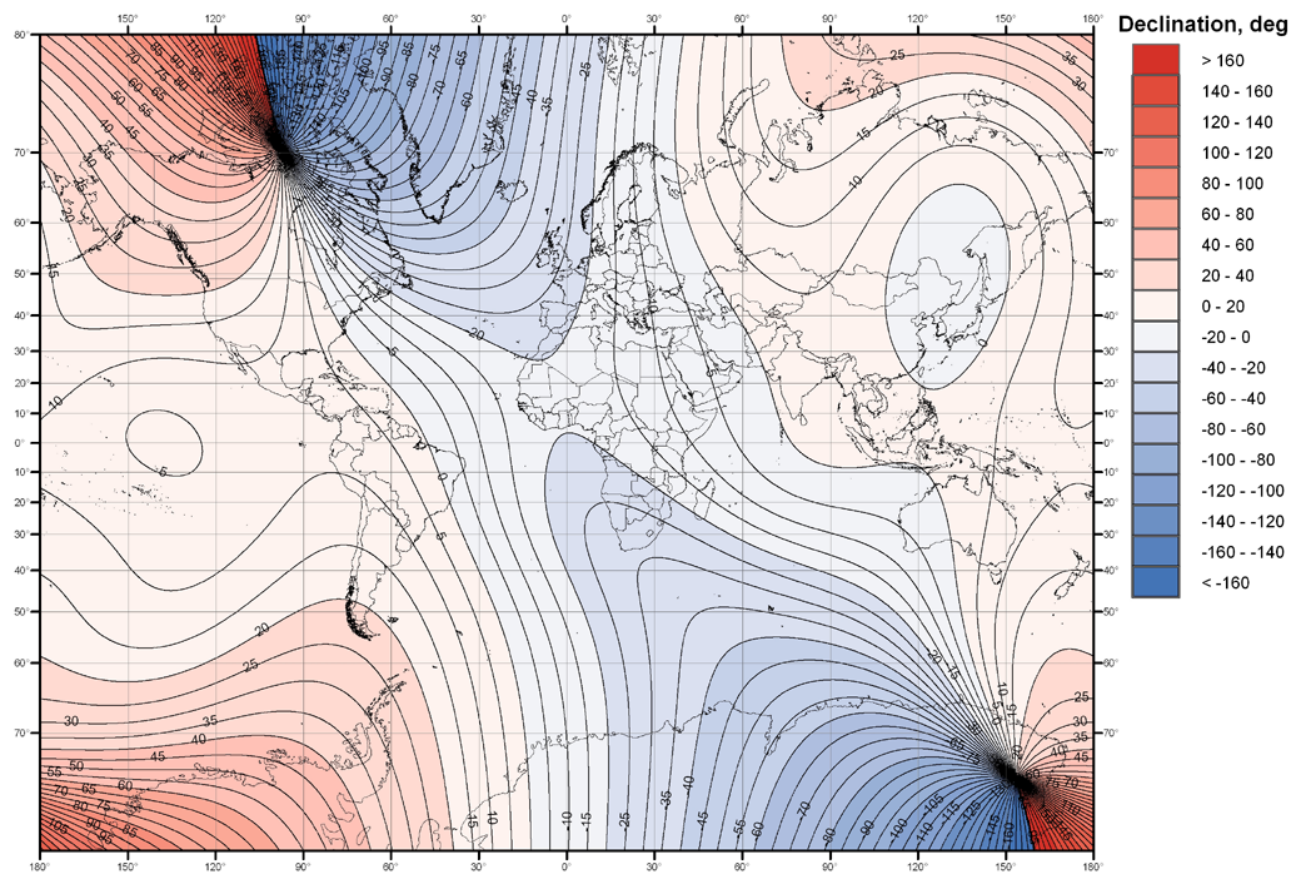

Figure 8. World map of isogons for 1830 calculated according to gufml model.

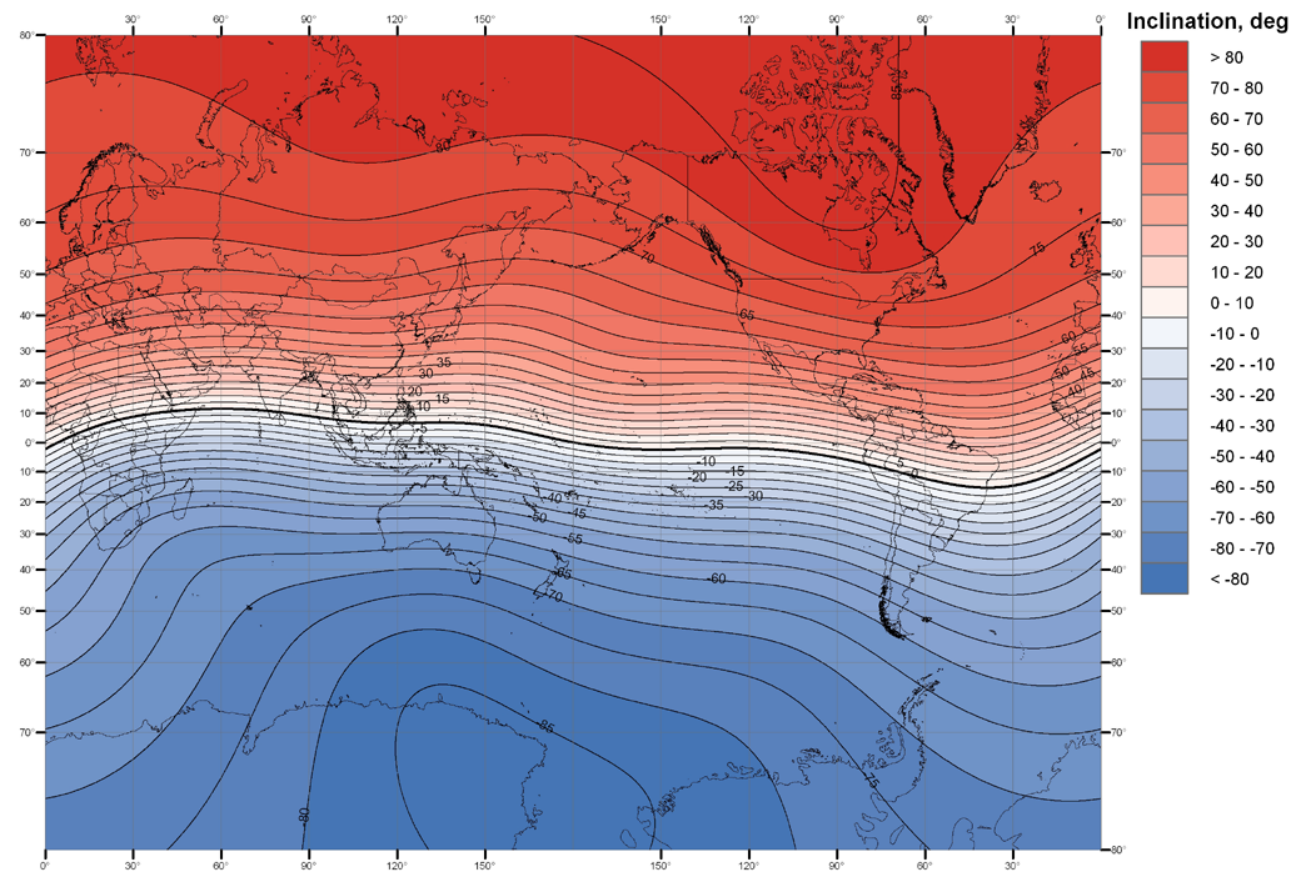

Figure 9. World map of isoclines for 1830 calculated according to gufml model. Magnetic equator is marked with a bold line. 


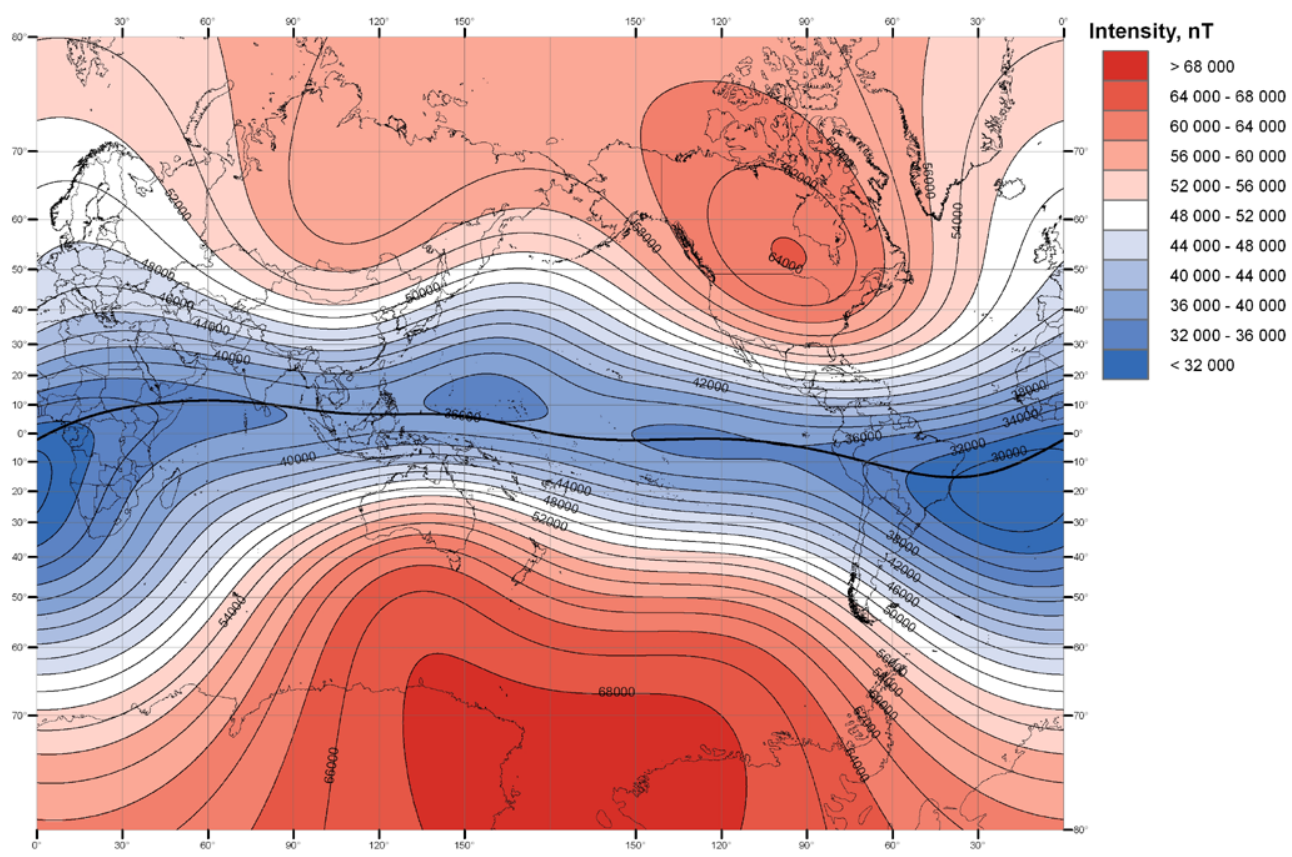

Figure 10. World map of total intensity for 1830 calculated according to gufml model. Magnetic equator is marked with a bold line.

\subsubsection{Inclination maps}

Figure 6 indicates "magnetic parallels", which we consider to be the magnetic inclination representation. Maps in Figs. 6 and 9 show, with the same detail the existence of the magnetic equator. Very nicely, von Humboldt's map indicates the knee in the zero curve in the South America region. Moreover, in both maps it is possible to see how well the northern and southern magnetic regions are delimited.

\subsubsection{Total intensity maps}

Comparing the maps of total intensity (Figs. 7 and 10), makes it possible to appreciate the quality of von Humboldt's map, at an epoch when measuring this magnetic field component was not completely known. Alexander von Humboldt's map (Fig. 7) shows isolines expressed in "Humboldt units" $(\mathrm{Hu})$. Both maps indicate the existence of the South Atlantic Anomaly, the area where the magnetic field intensity has its minimum values: the anomaly of $0.9 \mathrm{Hu}$, which equals to 31446.9 nT, on Fig. 7 covers nearly the same area as the anomaly defined by $32000 \mathrm{nT}$ on Fig. 10. Another remarkable feature present in von Humboldt's map and in the one built using the gufml model is given by the two lobes of maxima over the Canada and Siberia. Both maps indicate these maxima in the same regions, well-defined. The South magnetic pole region is somehow indicated by the maxima situated in Antarctica.

\subsection{Alexander von Humboldt and the secular variation}

We have indicated that von Humboldt became also involved in the organization of simultaneous widespread magnetic observations. These kind of simultaneous measurements have already been made in the middle of the 18th century, by Graham (in London) or Celsius (Uppsala). Arago, von Humboldt's friend, began systematic magnetic observations in Paris in 1814. von Humboldt noted that systematic and long-term magnetic observations should be done "gleich den astronomischen, fixe physikalische Observatorien und (wo möglich) über und unter der Erde, auf isolierten Felsspitzen und auf kleinen, vom Ozean umflossenen Inseln" - "similar to the astronomical ones, fixed physical observatories and (where possible) on and under the Earth, on isolated tips of rocks and on small islands surrounded by the ocean".

Late in 1828 , when von Humboldt came back to Berlin, he had a special non-magnetic building. This was realized in the garden of his friend A. Mendelssohn-Bartholdy (the famous composer's father) and operated until and operated until Mendelssohn-Bartholdy's death in 1835. During this period, von Humboldt helped Encke to get financial support to build the Berlin observatory. A non-magnetic house at the Berlin Astronomical Observatory was also built, and the installed instruments were a magnetometer for intensity measurements by Meyerstein, an inclinometer by Gambey, and a declinometer by Baurmann (Linthe, 2007). This was indeed a real magnetic observatory, and in order to run it properly von Humboldt involved other well-known scientists for observational tasks, such as Encke, Dirichlet, Poggendorff. 


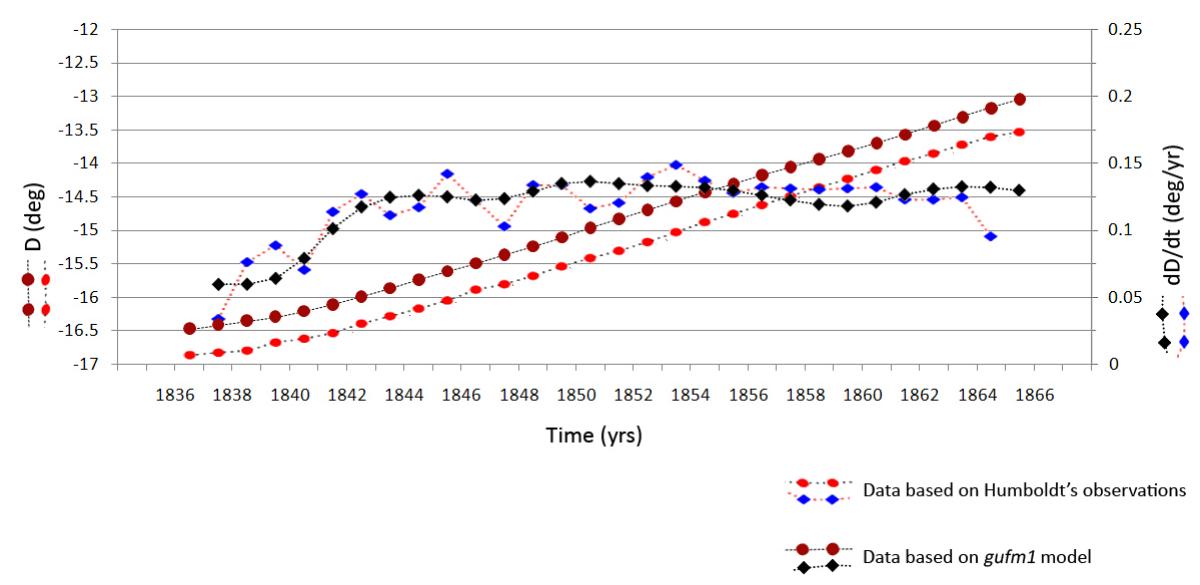

Figure 11. Declination values measured at Berlin observatory (latitude $52^{\circ} 30^{\prime}$, longitude $13^{\circ} 23^{\prime}$ ) founded by Alexander von Humboldt (bright red circles) and declination values calculated according to gufml model (dark red circles) at latitude $52.5^{\circ}$, longitude $13.4^{\circ}$ between 1836.5 and 1865.5. The corresponding time derivative values are plotted as well (blue rhombs for Humboldt's observations, black rhombs for $g u f m l$ data).

All the declination values measured at the Berlin observatory from 1836 to 1866 are plotted in Fig. 11. We also have computed the secular variation, the first time derivative and plotted it on the same graph. The observations made by von Humboldt and his successors are of great accuracy. It is clearly seen from comparison between curves built from observations made by von Humboldt, Dove, Encke, Dirichlet, Poggendorff and the curves calculated from gufml model: the difference between observed declination values and calculated ones is around $0.5^{\circ}$ (Fig. 11). This difference is too large to be an effect due to crustal biases. Indeed, we estimated the crustal biases for all field components recorded in Niemegk observatory, situated south-west of Berlin at a distance of about $100 \mathrm{~km}$, and they are less than a few tens of $\mathrm{nT}$, so the 0.5 degrees in declination between von Humboldt observations and those estimated from gufml model might be linked to a different source. One explanation could be that the measurement house was built nearby one of the main buildings of the Astronomical Observatory, affecting in measurements (however, we have not found a building distribution plan on the observatory area).

The secular variation indicates a change in the tendency around 1860 . This feature could be related to a similar one observed and discussed for some other declination series. Indeed, the change of trend in secular variation (known as a geomagnetic jerk) shown by the historical declination curve for Munich around 1861 (Korte et al., 2009) is presumably the one proposed around 1870 based on data from Paris and four other European locations by Alexandrescu et al. (1997).

\section{Conclusions}

Alexander von Humboldt is a great figure of the 19th century, a century, which saw a huge development in the field of geomagnetism, after a relatively quiet period. von Humboldt's lasting legacy has been the organization of a worldwide cooperation in the gathering of geophysical data with simultaneous measurements at pre- arranged dates. Moreover, the relative measurements, where he compared the period of oscillation of the same dip needle at different locations, gave some information on the spatial changes of the total field intensity, and the used units were named after his name, i.e. 1 Humboldt Unit = 34941 nT (Barraclough, 1978).

The worldwide geomagnetic observations made by von Humboldt (via the British Colonial Observatories, the Gottingen Magnetic Union, and the Russian chain of observatories) have been valuable ingredients in mapping the Earth's magnetic field. In this paper, we have compared von Humboldt's pioneering efforts on charting declination, inclination and total intensity and modern well-developed models, and have found favorable agreement between the two sets of charts, testifying the quality of von Humboldt's work.

Acknowledgements. We would like to thank Edward W. Cliver for organizing a fruitful scientific session dedicated to Alexander von Humboldt during the IAGA meeting in 2009 (von Humboldt's legacy after 150 years, http://www.iaga2009sopron.hu/scientific programme.html\#idch_01 and to involve us in efforts to recognize von Humboldt's contributions to geomagnetism.

Hannelore Podewski is thanked for her determined work on von Humboldt's traces. We would also like to thank Andrey Khokhlov and Evgeny Zhalkovsky from GC RAS for valuable consultations and assistance in preparing the paper. 
We wish to express our thanks to Angelo De Santis and two anonymous referees who gave so willingly of their time and expertise to improve the original manuscript.

MM role in this work is IPGP contribution 3102.

Edited by: K. Arora

Reviewed by: A. De Santis and two other anonymous referees

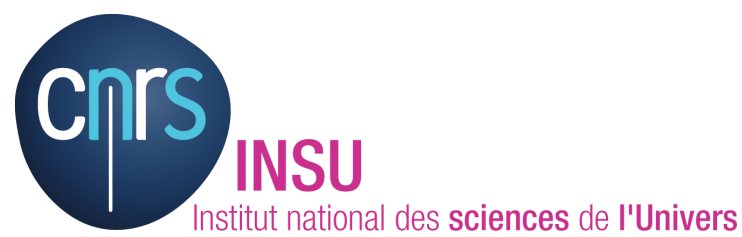

The publication of this article is financed by CNRS-INSU.

\section{References}

Alexandrescu, M., Courtillot, V., and Le Mouël, J.-L.: Geomagnetic field direction in Paris since the mid-XVIth century, Phys. Earth Planet. Inter., 98, 321-360, 1996.

Alexandrescu, M., Courtillot, V., and Le Mouël, J.-L.: High resolution secular variation of the geomagnetic field in western Europe over the last 4 centuries: Comparison and integration of historical data from Paris and London, J. Geophys. Res., 102, 2024520258, 1997.

Barraclough, D. R.: Spherical harmonic models of the geomagnetic field, Geomagn. Bull. Inst. Geol. Sci., 8, 1-66, 1978.

Berghaus, H.: Berghaus' Physikalischer Atlas, 1st Edn., Justus Perthes, Gotha, 1837-1848.

Botting, D.: Humboldt and the Cosmos, Michael Joseph, London, 1973.

Busse, F.: Humboldt, Alexander von (1759-1859), in: Encyclopedia of Geomagnetism and Paleomagnetism, edited by: Gubbins, D. and Herrero-Bervera, E., Earth Science Series, Springer, The Netherlands, 2007, 1054 pp., ISBN 978-1-4020-3992-8, 2007.

Clark, T. D. G.: Edmond Halley's voyages in the Paramore and the first isogonic chart of the Earth's magnetic field, in: Geomagnetism. Research past and present, edited bty: Schroeder, W., IAGA, Bremen-Roennebeck, 61-71, 2000.

Constable, C. G. and Korte, M.: Is the Earth's magnetic field reversing?, Earth Planet. Sc. Lett., 246, 1-2, 1-16, 2006.

Courtillot, V. and Le Mouël, J.-L.: The study of Earth's magnetism (1269-1950): A foundation by Peregrinus and subsequent development of geomagnetism and paleomagnetism, Rev. Geophys., 45, RG3008, doi:10.1029/2006RG000198, 2007.

Dumberry, M. and Finlay, C. C.: Eastward and westward drift of the Earth's magnetic field in the last three millennia, Earth Planet. Sc. Lett., 254, 146-157, 2007.

David Rumsey Map Collection: Cartography Associates http:// www.davidrumsey.com/, last access: 2010.

De Santis, A., Tozzia, R., and Gaya-Piqué, L. R.: Information Content and K-entropy of the Present Geomagnetic Field, Earth Planet. Sc. Lett., 218, 3-4, 269-275, 2004.

Gauss, C. F.: Allgemeine Theorie des Erdmagnetismus, in: Resultate aus den Beobachtungendes magnetischen Vereins im Jahre
1838, edited by: Gauss, C. F. and Weber, W., Leipzig, Germany, 1-57, 146-148, 1839.

Gillet, N., Lesur, V., and Olsen, N.: Geomagnetic core field secular variation models, Space Sci. Rev., doi:10.1007/s11214-0099586-6, 2009.

Hansteen, C.: Magnetiske Intensitets-Iagttagelser, Anstillede paa forskjellige Reiser i den nordlige Deel af Europa, Magazin for Naturvidenskaberne, 4, 268-316, 1824.

Hellmann, G.: Die Ältesten Karten der Isogonen, Isoklinen, Isodynamen, 1701, 1721, 1768, 1804, 1825, 1826, Berlin, 24 pp., 1895.

Hellmann, G.: Magnetische Kartographie in historisch-kritischer Darstellung, Abh. Kon. Preussischen met. Inst., 3, 61 pp., 1909.

Howarth, R. J.: Fitting Geomagnetic Fields before the Invention of Least Squares: II. William Whiston's Isoclinic Maps of Southern England (1719 and 1721), Ann. Sci., 60, 63-84, 2003.

Hulot, G., Khokhlov, A., and Le Mouël, J.-L.: Uniqueness of mainly dipolar magnetic fields recovered from directional data, Geophys. J. Int., 129, 347-354, 1997.

Hulot, G., Finlay, C. C., Constable, C. G., Olsen, N., and Mandea, M.: The Magnetic Field of Planet Earth, Space Sci. Rev., 152, 159-222, doi:10.1007/s11214-010-9644-0, 2010.

Humboldt, A. von and Biot, J.-B.: Sur les variations du magnetisme terrestre a differentes latitudes, Lu par M. Biot a la classe des sciences mathematiques et physiques de l'Institut National, le 26 frimaire an 13, 24, 1804.

Jackson, A., Jonkers, A. R. T., and Walker, M.: Four centuries of geomagnetic secular variation from historical records, Philos. Trans. R. Soc. London, Philos. Trans. Math. Phys. Eng. Sci., 358, 957-990, 2000.

Jackson, A., Jonkers, A. R. T., Mandea, M., and Murray, A.: Earth's magnetic field in the early 19th century from French sources, Geochem. Geophys. Geosyst., 4(7), 1054, doi:10.1029/2002GC000494, 2003.

Jackson, A. and Finlay, C. C.: Geomagnetic secular variation and applications to the core, in: Treatise on Geophysics, Vol. 5: Geomagnetism, Volume edited by: Kono, M., Series edited by: Schubert, G., Elsevier Publishers, Chapter 5.05, 147-193, 2007.

Jonkers, A. R. T., Jackson, A., and Murray, A.: Four centuries of geomagnetic data from historical records, Rev. Geophys., 41(2), 1006, doi:10.1029/2002RG000115, 2003.

Korte, M. and Mandea, M.: Magnetic poles and dipole tilt variation over the past decades to millennia, Earth Planets Space, 60, 937948, 2008.

Korte, M., Mandea, M., and Matzka, J.: A historical declination curve for Munich from different data sources, Phys. Earth Planet. In., 177(3-4), 161-172, 2009.

Lakhina, G. S., Tsurutani, B. T., Gonzalez, W. D., and Alex, S.: Humboldt,Alexander von and magnetic storms, in: Encyclopedia of Geomagnetism and Paleomagnetism, edited by: Gubbins, D. and Herrero-Bervera, E., Earth Science Series, Springer, The Netherlands, 1054 p., ISBN 978-1-4020-3992-8, 2007.

Linthe, H.-J., Observatories in Germany: Humboldt, Alexander von and magnetic storms, in: Encyclopedia of Geomagnetism and Paleomagnetism, edited by: Gubbins, D. and HerreroBervera, E., Earth Science Series, Springer, The Netherlands, 2007, 1054 p., ISBN 978-1-4020-3992-8, 2007.

Malin, S. R. C. and Barraclough, D. R.: Humboldt and the Earth's magnetic field, Q. Jl. R. astr. Soc. 32, 279-293, 1991. 
Mandea, M. and Purucker, M.: Measurements of the Earth's magnetic field from space, Surv. Geophys., 26(4), 415-459, doi:10.1007/s10712-005-3857-x, 2005.

Mandea, M.: Main field maps, in: Encyclopedia of Geomagnetism and Paleomagnetism, edited by: Gubbins, D. and HerreroBervera, E., Earth Science Series, Springer, The Netherlands, 2007, 1054 p., ISBN 978-1-4020-3992-8, 2007.

Mandea, M. and Korte, M.: Ancient sundials and maps reveal historical declination values, Eos Trans., 88(31), 310-311, 2007.
Press, W. H., Teukolsky, S. A., Vetterling, W. T., and Flannerty, B. P.: Numerical Recipes in C: The Art of Scientific Computing0, 2nd Edn., Cambridge University Press, New York, 1992.

Rupke, N. A.: Alexander von Humboldt: A Metabiography, ISBN10 0-226-73149-9, University of Chicago Press paperback Edn., 2008.

Wilcke, J. C.: Försök til en Magnetisk Inclinations-Charta, Konigl. Vetenskaps Akad. Handl., 29, table VI. (Reprinted by KrausThomson Org. Ltd., Nendeln, Liechtenstein, 1969), 1768. 